\title{
Preparation and Characterization of Ultra-thin
}

\section{Pd-Ag Alloy Membranes}

\author{
Renguo SONG ${ }^{1) \dagger}$, Zhanguo ZHANG ${ }^{2)}$, Chao $W A N G^{1)}$, Hai $L I^{1)}$ and Zhixiu $W A N G^{1)}$ \\ 1) School of Materials Science and Engineering, Changzhou University, Changzhou 213164, China \\ 2) National Institute of Advanced Industrial Science and Technology (AIST), 16-1 Onogawa, Tsukuba, Ibaraki 3058569, \\ Japan \\ [Manuscript received 18 March 2013, in revised form 28 March 2013] \\ (C) The Chinese Society for Metals and Springer-Verlag Berlin Heidelberg
}

\begin{abstract}
Ultra-thin Pd-Ag alloy membranes were prepared initially by cold rolling, and it was found that there exist a large number of defects such as pinholes or cracks in the as-rolled membranes. Subsequently, these defects were repaired using electroless plating technique. The morphologies of the membranes have been examined by scanning electron microscopy (SEM). It was observed in some as-repaired membranes that the defects were disappeared. A hydrogen permeation study has demonstrated that the as-repaired Pd-Ag alloy membranes were of high hydrogen permeation flux and hydrogen selectivity.
\end{abstract}

\section{KEY WORDS: Pd-Ag alloy membrane; Cold rolling; Electroless plating; Hydrogen permeation}

\section{Introduction}

Hydrogen is essential for the production of clean fuel. Faced to lower-grade crude oil and stricter environmental standards, refinery will need more hydrogen to reduce the amounts of metals, sulfur and nitrogen in the hydrocarbon fuel. Also, the tougher legislation for air pollution emissions is expected to increase the use of hydrogen as an alternate fuel for zeroemission vehicles. In order to meet these challenges, improvements must be made in the production, separation, purification and utilization of hydrogen. Hydrogen selective membranes have been the focus of intensive study in recent years ${ }^{[1-5]}$. The potential applications of hydrogen selective membranes include separation and recovery of hydrogen from process stream, purification of hydrogen for fuel cell application and membrane reactors. Membrane reactors have the advantage of combining chemical reaction and separation in a single unit. It has been demonstrated that the selective removal of hydrogen across the membrane during the dehydrogenation can result in supra-

† Corresponding author. Prof., Ph.D.; Tel: +86 519 86330069; Fax: +86 519 86330069; E-mail: songrg@cczu.edu.cn (Renguo SONG)

DOI: $10.1007 / \mathrm{s} 40195-013-0151-7$ equilibrium conversions. Moreover, high purity hydrogen can be recovered from the reaction.

$\mathrm{Pd}$ and $\mathrm{Pd}$ alloy membranes exhibit very high performance in terms of hydrogen permeability because of the high solubility and diffusivity of the hydrogen isotopes in their lattice. In particular, $\mathrm{Pd}$ Ag alloy with silver content of $23-25$ at.\% shows a very high chemical and mechanical stability. The addition of $\mathrm{Ag}$ into the $\mathrm{Pd}$ membrane has been used to improve their resistance to hydrogen embrittlement. Therefore, $\mathrm{Pd}$ and $\mathrm{Pd}-\mathrm{Ag}$ membranes have received growing attention for catalytic membrane reactor and hydrogen purification applications during the past three decades ${ }^{[6-14]}$. Up till now, many methods have been proposed and developed to prepare $\mathrm{Pd}$ and Pd-based membranes including physical vapor deposition (PVD), sputtering and magnetron sputtering, chemical vapor deposition (CVD), electroless plating, cold rolling and so on ${ }^{[15]}$. Among these techniques, electroless plating is the most attractive preparation method because it provides strong advantages such as uniformity of deposits on complex shapes, low cost as well as very simple equipment ${ }^{[16-18]}$. For Pd membrane preparation using electroless plating technique, $\mathrm{Pd}$ particles are generally reduced from the plating solution of amine complex of $\mathrm{Pd}$ in the presence of reducing agents and then grow on $\mathrm{Pd}$ nuclei which 
are presented on the target surface through a successive activation and sensitization procedure and which also act as a catalyst for the reduction of the Pd complexes. This is so-called autocatalytic process of electroless plating.

In the present work, ultra-thin $\mathrm{Pd}-\mathrm{Ag}$ alloy membranes with a large number defects have been obtained starting from a $\mathrm{Pd}-\mathrm{Ag}$ alloy foil with the thickness of $50 \mu \mathrm{m}$ by cold-rolling, and then they were repaired by electroless plating. The effects of repair on the hydrogen/nitrogen permeation and separation were studied preliminarily.

\section{Experimental}

\subsection{Preparation of thin $\mathrm{Pd}-\mathrm{Ag}$ alloy foils}

A cold rolling process has been operated starting from commercial Pd-Ag (25 wt.\%) alloy foil, $50 \mu \mathrm{m}$ thick. This alloy sheet has been rolled up to $5 \mu \mathrm{m}$ ultra-thin Pd-Ag alloy membrane by ten steps. This membrane prepared possessed defects.

\subsection{Repair of cold rolled ultra-thin Pd-Ag alloy mem- branes}

The cold rolled ultra-thin $\mathrm{Pd}-\mathrm{Ag}$ alloy membrane with a large number defects was repaired by electroless plating technique. The $\mathrm{Pd}-\mathrm{Ag}$ alloy membrane was immersed in the plating solution for $4 \mathrm{~h}$ at various temperatures of $309-346 \mathrm{~K}$. The composition of the plating bath as follows: $2 \mathrm{~g} / \mathrm{L} \mathrm{PdCl}_{2}, 340 \mathrm{~mL} / \mathrm{L}$ $\mathrm{NH}_{4} \mathrm{OH}, 30 \mathrm{~g} / \mathrm{L} 2 \mathrm{Na}$.EDTA, $10 \mathrm{~mL} / \mathrm{L} \mathrm{N}_{2} \mathrm{H}_{4}$. The $\mathrm{pH}$ value of the plating solution is $8 . \mathrm{Pd}$ deposited on the cold-rolled ultra-thin $\mathrm{Pd}-\mathrm{Ag}$ membrane surface from the plating solution to form a continuous film. This repaired membrane was then used for permeation measurements with hydrogen and nitrogen. The membranes were kept in an oven overnight at $313 \mathrm{~K}$ for all drying steps and were weighted before and after electroless plating. The Pd film thickness was estimated from the weight gain.

\subsection{Characterization of ultra-thin $P d-A g$ alloy mem- branes}

The morphologies of the membranes were studied by scanning electron microscopy (SEM), and elemental analysis was performed using energy dispersive Xray spectroscopy (EDS).

\subsection{Permeation measurement}

The ultra-thin $\mathrm{Pd}-\mathrm{Ag}$ alloy membrane with diameter of $8 \mathrm{~mm}$ was positioned in a stainless steel reactor, as shown in Fig. 1. Hydrogen and nitrogen permeation through the $\mathrm{Pd}-\mathrm{Ag}$ alloy membrane was measured with pure hydrogen or nitrogen. Feed gas flowed through the upside of the reactor and the per-

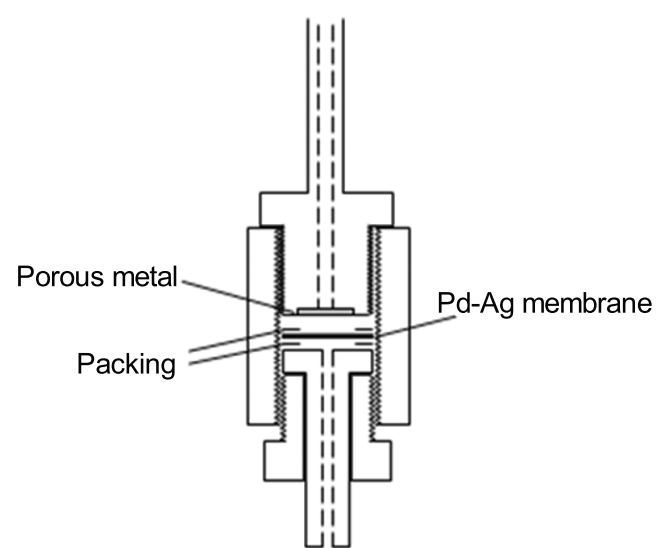

Fig. 1 Schematic diagram of the membrane reactor

meated gases were collected in the downside of the reactor. A gold furnace was used to heat the gases.

\section{Results and Discussion}

\subsection{Ultra-thin Pd-Ag alloy membranes preparation}

Fig. 2 shows the surface morphologies of ultra-thin $\mathrm{Pd}-\mathrm{Ag}$ alloy membranes prepared by cold rolling. It can be seen from Fig. 2 that there exist a large number of defects such as pinholes or cracks in the cold rolled ultra-thin $\mathrm{Pd}-\mathrm{Ag}$ alloy membranes. The maximum diameter of the pinhole is about $20 \mu \mathrm{m}$ (see Fig. 2(b)), and the maximum length of the crack is about $30 \mu \mathrm{m}$ (see Fig. 2(c)). These defects maybe caused by socalled work hardening during cold rolling of $\mathrm{Pd}-\mathrm{Ag}$ alloy foil.

There is no universal means for measuring the thickness of the metallic films. Of the various available methods, weight-gain, differential thickness and SEM methods are considered to be most common. In the present research work, the $\mathrm{Pd}$ film thickness was measured by the weight-gain method. In this method the weight difference between the cold rolled $\mathrm{Pd}-\mathrm{Ag}$ alloy membrane and electroless plating $\mathrm{Pd}-\mathrm{Ag}$ alloy membrane is divided by product of the membrane surface area and the Pd density to obtain the approximate film thickness.

Fig. 3 shows the effect of the electroless plating temperature on the $\mathrm{Pd}$ film thickness. It was indicated that the thickness of the $\mathrm{Pd}$ film deposited on the surface of cold rolled untra-thin $\mathrm{Pd}-\mathrm{Ag}$ membrane by electroless plating increases with the plating temperature increasing when the temperature is lower than $325 \mathrm{~K}$, while it decreases with the plating temperature increasing when the temperature is higher than $325 \mathrm{~K}$. These results suggested that the Pd deposition rate increases with the plating temperature increasing when the temperature is lower than $325 \mathrm{~K}$, while it decreases dramatically with the plating temperature increasing when the temperature is higher 


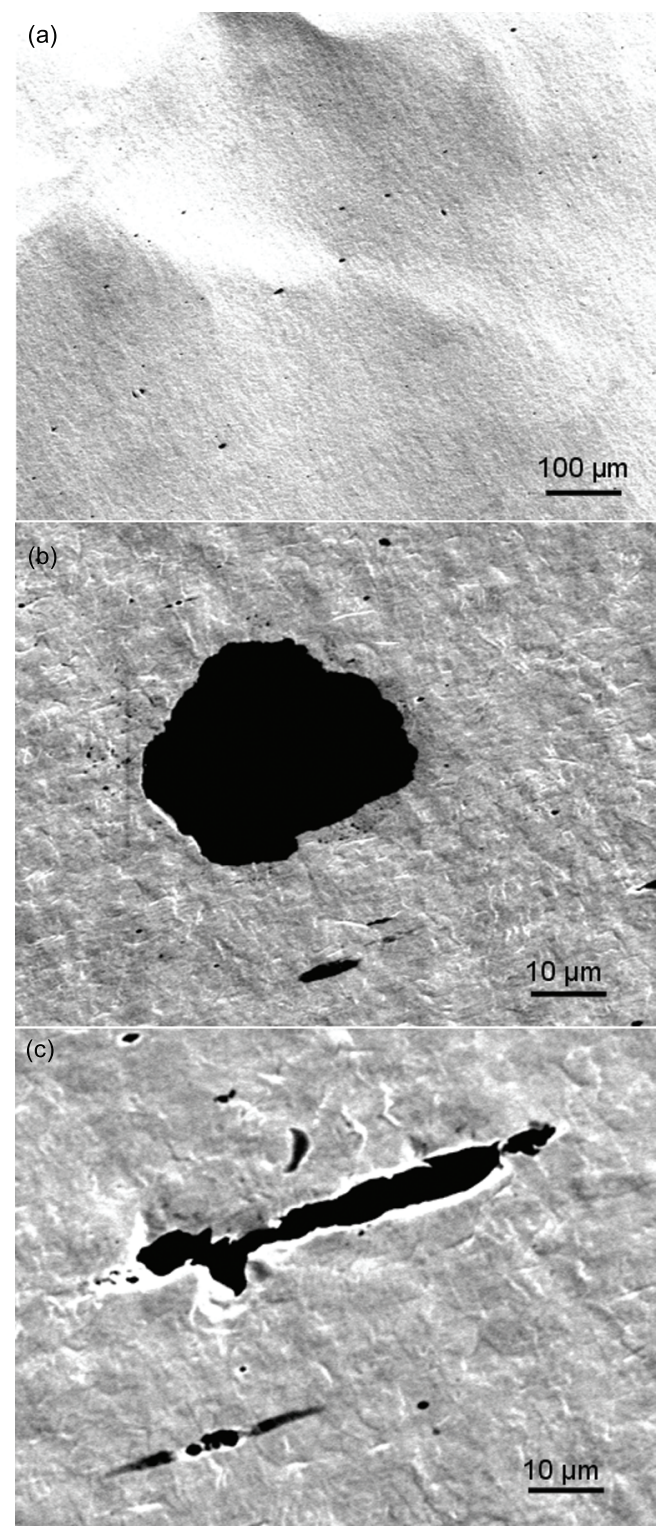

Fig. 2 SEM images showing the surface morphology of ultra-thin $\mathrm{Pd}-\mathrm{Ag}$ alloy membranes prepared by cold rolling: (a) low magnification image; (b) and (c) high magnification images

than $325 \mathrm{~K}$.

Fig. 4 shows the surface morphologies of $\mathrm{Pd}-\mathrm{Ag}$ alloy membranes repaired by electroless plating under various temperatures for $4 \mathrm{~h}$. It can been seen from Figs. 4(a-c) that all the defects formed during cold rolling disappeared on the ultra-thin Pd-Ag alloy membranes after repair by electroless plating, however, there still exist a small number of defects on as-repaired membranes, as shown in Fig. 4(d) and Fig. 4(e). In addition, Pd deposits slowly and react is inhibited when the plating temperature is low (309 K), some characteristics of cold rolled Pd-Ag alloy membrane still remained (see Fig. 4(a)). The deposition rate increases rapidly when the plating temperature is high $(326 \mathrm{~K})$, the characteristics of cold rolled $\mathrm{Pd}-\mathrm{Ag}$ membrane disappear at all and contin-

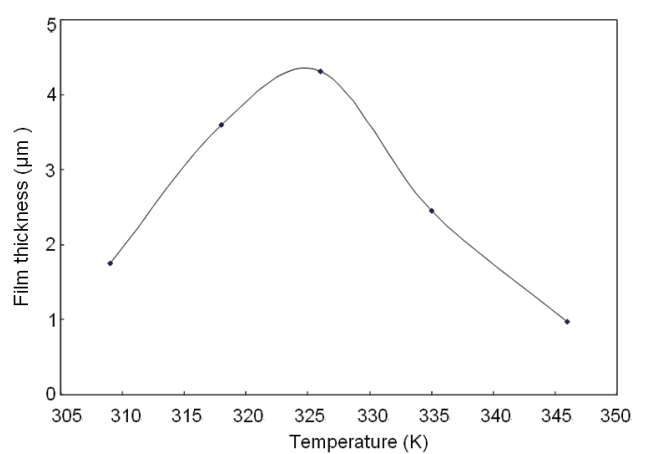

Fig. 3 Effect of plating temperature on Pd film thickness (plating time is $4 \mathrm{~h}$ )

uous and dense films are formed (see Fig. 4(b) and Fig. 4(c)). However, the deposition rate decreases very quickly when the plating temperature is higher than $326 \mathrm{~K}$ (see Fig. 3). This is because the ammonia in the plating solution volatilizes very fast under so high temperature, the plating solution is not stable and easy to decompose, and a large number of metallic ions are easy deposited on the wall of container. A large amount of nucleus are formed in a short time, some nucleus not growing are covered by the fine nucleus formed subsequently. Therefore, it induces the plating film loose and dark that a large number of irregular nucleus deposition (see Fig. 4(d) and Fig. 4(e)). When the plating temperature is $318 \mathrm{~K}$, the morphology of obtained film is the most ideal. This is because the nucleus grows sufficiently and it has a definite grow velocity, resulting in the film is covered by new nucleus constantly during the layer growth process. Finally, a dense and continuous film is formed (see Fig. 4(b)).

In order to study the chemical composition of the as-repaired membranes shown in Fig. 4, elemental analysis of the surfaces of as-repaired membranes were performed using EDS, as shown in Fig. 5. It is indicated that there exist a small amount of $\mathrm{Ag}$ on the as-repaired membranes in the case of plating temperatures are 309, 326 and $346 \mathrm{~K}$, also there exist other impurities such as $\mathrm{C}, \mathrm{P}, \mathrm{O}$ and $\mathrm{S}$ elements. When plating temperature is $318 \mathrm{~K}$, there exist no $\mathrm{Ag}$ and the content of $\mathrm{Pd}$ is $85.55 \mathrm{wt} . \%$, which is the highest one among all the as-repaired membranes. It should be pointed out that we could not know exactly where the element $\mathrm{C}$ and other impurities came from; perhaps they are originated from the contamination of the samples. These EDS results suggested that Pd film deposited by electroless plating at $318 \mathrm{~K}$ is the most dense one among all the as-repaired membranes. This is consistent with the SEM observations mentioned above.

\subsection{Hydrogen/nitrogen permeation measurements}

In order to check the effect of the repair of cold rolled ultra-thin Pd-Ag alloy membrane on the hydrogen permeation and selectivity, a hydrogen/nitrogen 


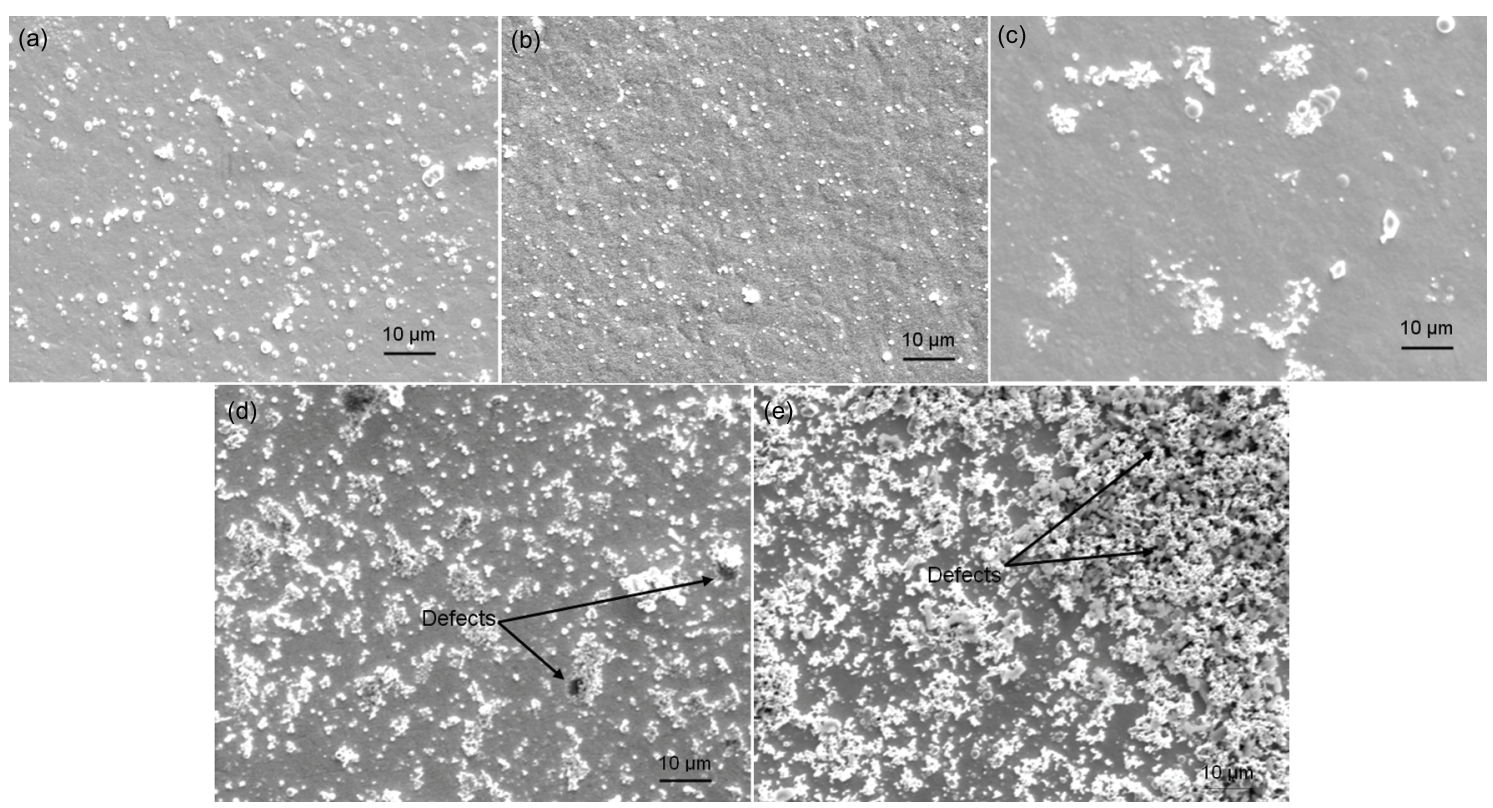

Fig. 4 SEM images showing the surface morphology of Pd-Ag alloy membranes repaired by electroless plating for $4 \mathrm{~h}$ at various plating temperatures: (a) $309 \mathrm{~K}$; (b) $318 \mathrm{~K}$; (c) $326 \mathrm{~K}$; (d) $335 \mathrm{~K}$; (e) $346 \mathrm{~K}$
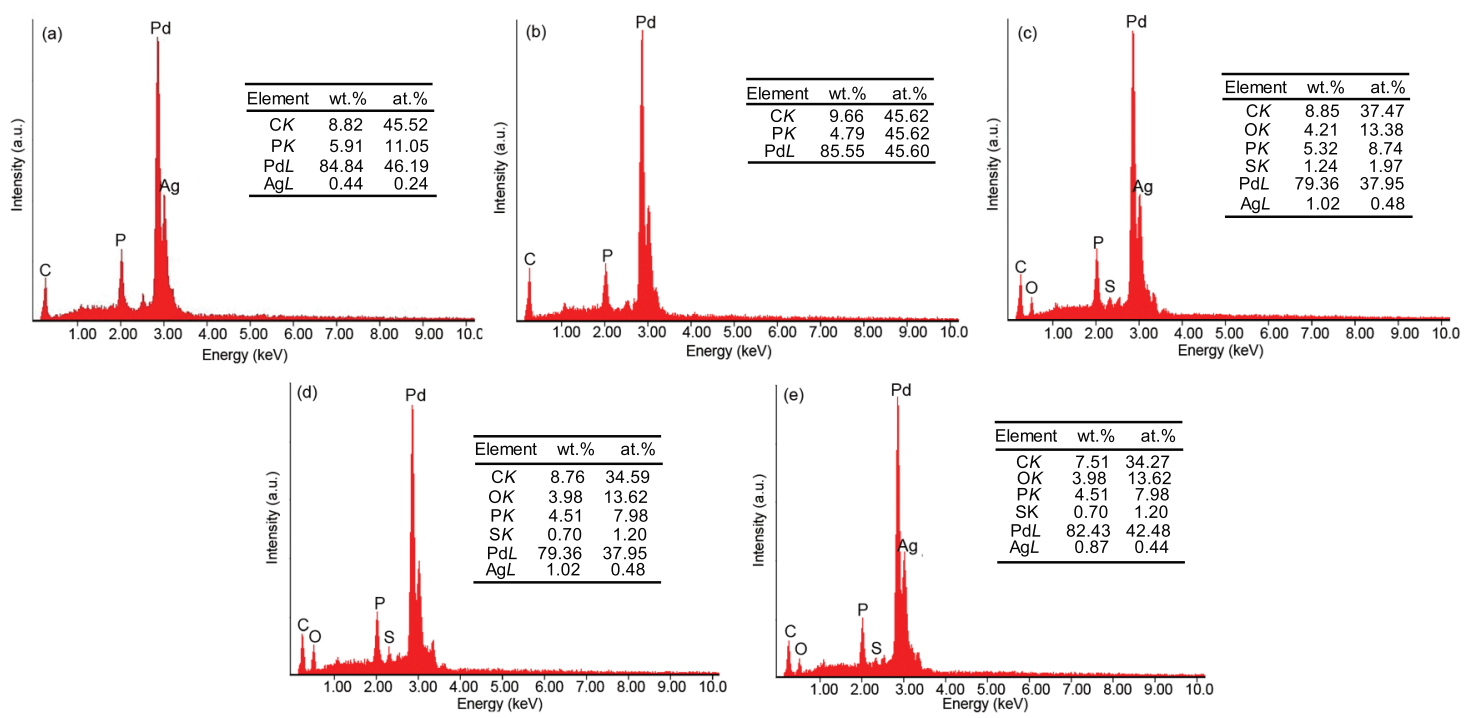

Fig. 5 Elemental analyses for the surfaces of Pd-Ag alloy membranes repaired by electroless plating for $4 \mathrm{~h}$ at various plating temperatures: (a) $309 \mathrm{~K}$; (b) $318 \mathrm{~K}$; (c) $326 \mathrm{~K}$; (d) $335 \mathrm{~K}$; (e) $346 \mathrm{~K}$

permeation measurement for cold rolled and asrepaired $\mathrm{Pd}-\mathrm{Ag}$ alloy membranes by electroless plating under various plating temperature has been carried out at $773 \mathrm{~K}$ and hydrogen differential pressure of $0.196 \mathrm{MPa}$, respectively. The results of the present work and the data from Ref. [17] are listed in Table 1. It can be seen from Table 1 that under the same conditions the nitrogen permeation flux decreases dramatically while the hydrogen/nitrogen permeation ratio increases by about three orders of magnitude after repair, although the hydrogen permeation flux also decreased following the repair process. Simultaneously, it can also be seen that the nitrogen perme-linebreak ation flux and hydrogen/nitrogen permeation ration are closed dependent on the electroless plating temperature. This may be attributed to the total thickness of as-repaired $\mathrm{Pd}-\mathrm{Ag}$ alloy membranes change with changing the plating temperature. The hydrogen/nitrogen permeation ration for as-repaired $\mathrm{Pd}$ $\mathrm{Ag}$ alloy membrane with the plating temperature of $326 \mathrm{~K}$ is the highest one, which is much higher than the data reported in Ref. [17]. This is because the $\mathrm{Pd}$ film deposited under such a temperature is the densest one among all the membranes. These results indicated that electroless plating technique adopted could not only repair the defects present in cold rolled 
Table 1 Hydrogen/nitrogen permeation results of the cold rolled Pd-Ag membrane and the as-repaired $\mathrm{Pd}-\mathrm{Ag}$ membranes

\begin{tabular}{|c|c|c|c|c|}
\hline \multirow[t]{2}{*}{ Membrane } & \multirow[t]{2}{*}{ Membrane thickness $(\mu \mathrm{m})$} & \multicolumn{2}{|c|}{ Permeation flux $\left(\mathrm{mL} /\left(\mathrm{cm}^{2} \cdot \min \right)\right)$} & \multirow[t]{2}{*}{$\mathrm{H}_{2} / \mathrm{N}_{2}$ ratio } \\
\hline & & $\mathrm{N}_{2}$ & $\mathrm{H}_{2}$ & \\
\hline Cold rolled $\mathrm{Pd}-\mathrm{Ag}$ membrane & 5.00 & 14.2 & 80.5 & 5.7 \\
\hline As-repaired Pd-Ag membrane (309 K) & 6.75 & 0.0083 & 52.5 & 6325 \\
\hline As-repaired Pd-Ag membrane (318 K) & 8.60 & 0.0069 & 50.4 & 7304 \\
\hline As-repaired Pd-Ag membrane (326 K) & 9.31 & 0.0061 & 48.2 & 7902 \\
\hline As-repaired Pd-Ag membrane (335 K) & 7.45 & 0.05 & 66.8 & 1336 \\
\hline As-repaired Pd-Ag membrane (346 K) & 5.97 & 0.08 & 70.3 & 879 \\
\hline As-repaired $\mathrm{Pd} / \alpha-\mathrm{Al}_{2} \mathrm{O}_{3}$ membrane ${ }^{[17]}$ & 10.3 & 0.04 & 40.1 & 970 \\
\hline
\end{tabular}

Note: temperature in the bracket is plating temperature

ultra-thin Pd-Ag alloy membrane, but also improve the selectivity of the membrane without a large decrease of the hydrogen permeation. Therefore, the repairs were effective.

\section{Conclusions}

Ultra-thin Pd-Ag alloy membranes with thickness of $5 \mu \mathrm{m}$ have been successfully obtained by cold rolling, however, there exist a large number defects such as pinholes or cracks in the as-rolled $\mathrm{Pd}-\mathrm{Ag}$ alloy membranes. Electroless plating technique was employed to repair the defects in the as-rolled $\mathrm{Pd}-\mathrm{Ag}$ alloy membranes, and the as-repaired membrane exhibited a large hydrogen permeation flux and very high hydrogen selectivity. The electroless plating temperature has a considerably effects on the morphologies and the microstructure of the deposited $\mathrm{Pd}$ films on the surface of as-rolled Pd-Ag alloy membranes.

\section{Acknowledgement}

This work was financially supported by the Priority Academic Program Development of Jiangsu Higher Education Institutions (PAPD).

\section{REFERENCES}

[1] F.R. Garcia-Garcia, L. Torrente-Murciano, D. Chadwick and K. Li, J. Membr. Sci. 405 (2012) 30.

[2] J.A. Calles, R. Sanz and D. Alique, Int. J. Hydrog.
Energy 37 (2012) 6030.

[3] T. Saito, M. Seshimo, K. Akamatsu, K. Miyajima and S. Nakao, J. Membr. Sci. 392 (2012) 95.

[4] X.J. Hu, W.D. Chen and Y. Huang, Int. J. Hydrog. Energy 35 (2010) 7803.

[5] L.S. Wang, R. Yoshiie and S. Uemiya, J. Membr. Sci. 306 (2007) 1.

[6] S. Niwa, M. Eswaramoorty, J. Nair, A. Raj, N. Itoh, H. Shoji, T. Namba and F. Mizukami, Science 295 (2002) 105.

[7] S. Ilias, N. Su, U.I. Udo-Aka and F.G. King, Sep. Sci. Technol. 32 (1997) 487.

[8] W.H. Lin, C.S. Hsiao and H.F. Chang, J. Membr. Sci. 322 (2008) 360.

[9] J.N. Keuler, L. Lorenzen, R.D. Sanderson, V. Prozesky and W.J. Przybylowicz, Thin Solid Films 347 (1999) 91.

[10] A.W. Li, W.Q. Liang and R. Hughes, Catal. Today 56 (2000) 45.

[11] S. Tosti, A. Adrover, A. Basile, V. Camilli, G. Chiappetta and V. Violante, Int. J. Hydrog. Energy 28 (2003) 105.

[12] J. Shu, B.P.A. Grandjean, A. Van Neste and S. Kaliaguine, Can. J. Chem. Eng. 69 (1991) 1036.

[13] R. Hughes, Membr. Technol. 3 (2001) 9.

[14] Z.Y. Li, J. Membr. Sci. 78 (1993) 247.

[15] S. Tosti, L. Bettinali, S. Castelli, F. Sarto, S. Scaglione and V. Violante, J. Membr. Sci. 196 (2002) 241.

[16] H.B. Zhao, G.X. Xiong and G.V. Baron, Catal. Today 56 (2000) 89.

[17] A.W. Li, W.Q. Liang and R. Hughes, Sep. Purif. Technol. 15 (1999) 113.

[18] B.K.R. Nair, J. Choi and M.P. Harold, J. Membr. Sci. 288 (2007) 67. 